\title{
Pengaruh Latihan Pylometric terhadap Performa Olahraga: Kajian Literatur
}

\author{
Saraswati Dharani, Oce Wiriawan, Edy Mintarto \\ Pendidikan Olahraga, Universitas Negeri Surabaya \\ dharaniputri19@gmail.com
}

\begin{abstract}
Plyometric training is a form of training that uses the body as a load in training to increase physical capacities such as explosive power, speed, and strength. This physical capacity is needed in various forms of sports such as small field sports, large field sports, water sports, even for injury prevention. Each type of exercise requires different volume, frequency and intensity. This article aims to determine the effect that plyometric training can have on performance in sports. The method used is a literature review of previous research related to the effect of using plyometric training on various types of sports. The results showed that the use of plyometric exercises improved the performance of physical capacity, both in land and water sports.
\end{abstract}

Keywords: power, strength, speed, explosive training

\begin{abstract}
Abstrak. Latihan plyometric merupakan bentuk latihan yang menggunakan tubuh sebagai beban dalam latihan untuk meningkatkan kapasitas fisik seperti daya ledak, kecepatan, dan kekuatan. Kapasitas fisik ini diperlukan dalam berbagai bentuk olahraga seperti olahraga lapangan kecil, olahraga lapangan besar, olahraga air, bahkan untuk pencegahan cidera. Setiap jenis olahraga memerlukan volume, frekuensi, dan intensitas yang berbeda-beda. Artikel ini memiliki tujuan untuk mengetahui pengaruh yang diberikan oleh latihan plyometric terhadap performa dalam olahraga. Metode yang digunakan adalah kajian literatur terhadap penelitian terdahulu terkait pengaruh penggunaan latihan plyometric terhadap berbagai macam jenis olahraga. Hasil penelitian menunjukkan bahwa penggunaan latihan plyometric meningkatkan performa kapasitas fisik, baik dalam olahraga darat dan olahraga air.
\end{abstract}

Kata kunci: daya ledak, kekuatan, kecepatan, latihan eksplosif

\section{PENDAHULUAN}

Latihan merupakan kegiatan yang memiliki peran penting dalam menentukan prestasi seseorang. Untuk mendapatkan hasil yang maksimal, latihan dilakukan secara berulangulang. Dalam olahraga, latihan sering dikaitkan dengan usaha pencapaian prestasi dalam dan menjaga kebugaran fisik. Secara hierarki latihan menyangkut faktor fisik, teknik, taktik, dan psikologi (Bompa, 1994). Untuk mendapatkan prestasi yang maksimal dalam olahraga, keempat faktor tersebut harus dilaksanakan dengan porsi yang tepat secara maksimal.

Setiap faktor memiliki jenis latihan yang berbeda-beda. Untuk peningkatan faktor fisik seseorang, maka harus menggunakan latihan dengan melibatkan usaha perubahan kondisi fisik meliputi kecepatan, kekuatan, power, dan kelincahan. Setiap kondisi fisik memiliki bentuk latihan yang berbeda-beda untuk meningkatkan performanya. Salah satu bentuk latihan yang bisa digunakan untuk meningkatkan performa kondisi fisik adalah latihan plyometrik.

Plyometric merupakan jenis latihan fisik yang menekankan pada pembentukan power pada tubuh bagian bawah (Davies, Riemans, \& Manske, 2015). Jenis latihan ini efektif apabila digunakan untuk jenis olahraga yang memerlukan tumpuan pada kaki seperti anggar (Tsolakis, Kostaki, \& Vagenas, 2010; Guilhem, 2014; Chen, 2017). Beberapa peneliti menemukan bahwa LP memiliki risiko cidera yang cukup tinggi bagi pemula (Chmielewski, 2006). Latihan ini sesuai apabila digunakan oleh atlet profesional, namun untuk orang awam, diperlukan panduan dan pengawasan yang cukup ketat (Duda, 1988; Chu, 1989; Wathen \& Trainer, 1993; Davies \& Mathenson, 2001; Chmielewski, 2006). LP 
Jurnal Ilmiah Mandala Education

http://ejournal.mandalanursa.org/index.php/JIME/index

Terakreditasi Peringkat 4 (No. SK: 36/E/KPT/2019)

mampu menyebabkan cidera yang cukup serius pada tulang belakang dan anggota gerak tubuh bagian bawah.

Di samping banyaknya risiko cidera yang dimiliki oleh LP, jenis latihan ini juga memiliki banyak manfaat. Jenis olahraga lapangan outdoor (Cadore et al., 2013; Supriyanto, 2018), lapangan indoor (Khifa et al., 2010; Turner et al., 2016), dan olahraga individu (Bshop et al., 2009) menggunakan LP. Sejalan dengan hal tersebut, jenis latihan yang digunakan bermaca-macam seperti single leg, double leg, satu tempat dan lain-lain (Fowler et al., 1995; Wilkerson et al., 2004; De Villarreal, Requena, \& Newton, 2010). Meskipun jenis latihan lebih banyak terfokus pada latihan tubuh bagian bawah, plyometric juga dapat digunakan untuk tubuh bagian atas seperti pada olahraga lempar (Pezzullo, Karas, \& Irrgang, 1995).

LP merupakan jenis latihan dengan pelaksanaan yang cukup sederhana, dan dapat dilakukan di dalam rumah dengan manfaat yang besar. Latihan ini juga dapat digunakan dalam menunjang kesehatan tubuh. Beberapa peneliti menemukan bahwa LP mampu menurunkan berat badan dan melancarkan peredaran darah. Selain itu keluhan karena sulit tidur juga dapat diatasi dengan menggunakan LP.

LP bersifat eksplosif, sehingga pengukuran performa yang akurat diperlukan untuk mengetahui perubahan yang terjadi (Booth \& Orr, 2016). Pengukuran peningkatan performa pada LP yang paling umum menggunakan force plate (contact time, ground reaction forces, takeoff velocity) (Wallace et al., 2010; Donoghue, Shimojo, \& Takagi, 2011; Ebben et al., 2011; García-Massó et al., 2011) dan dengan menggunakan elektromiografi (Ebben, Simenz, \& Jensen, 2008; García-Massó et al., 2011). Pengukuran relatif seperti reactive strength index dapat digunakan apabila tidak terdapat peralatan penunjang yang lain (Ebben \& Petushek, 2010).

Tujuan dari artikel ini adalah melakukan kajian literatur pada LP dan pengaruhnya terhadap peningkatan performa berbagai jenis olahraga. Dengan demikian tujuan dari artikel ini adalah memberikan pedoman praktis dalam penggunaan program latihan plyometric secara efektif dan aman.

\section{METODE}

Metode yang digunakan dalam menjabarkan permasalahan dalam penelitian ini adalah dengan kajian literatur terhadap referensireferensi dan hasil penelitian yang relevan (Notar \& Cole, 2010). Hasil kajian terhadap beberapa literatur tersebut kemudian dilanjutkan melalui Focus Group Discussion (FGD). Referensi yang digunakan meliputi buku-buku dan penelitian terdahulu tentang LP.

\section{HASIL DAN PEMBAHASAN Pengaruh LP dalam Program Latihan}

LP terdiri dari dua komponen yaitu komponen horizontal dan vertikal. Komponen horizontal artinya dapat digunakan bersamaan dalam sebuah program latihan. Setiap program latihan memberikan pengaruh yang bervariasi sesuai dengan karakteristik program latihan (Booth \& Orr, 2016). Umumnya hal ini disebabkan oleh tujuan spesifik dari program latihan yang digunakan. Sebagai contoh pemain tenis akan menggunakan latihan untuk meningkatkan kelincahan (Fernandez-Fernandez, 2016) dan pemain renang akan meningkatkan kekuatan kaki (Rebutini et al., 2016; Sammoud et al., 2019). Untuk meningkatkan kekuatan dan kelincahan lebih disarankan menggunakan komponen horizontal pada LP (Salonikidis \& Zafeiridis, 2008; Rebutini Een al., 2016). Komponen horizontal juga diperlukan oleh seorang pelari yang memerlukan kecepatan pergerakan kaki (Turner et al., 2015). Sedangkan pemain bola voli dan basket tidak hanya memerlukan kelincahan, namun juga memerlukan power untuk melakukan lompatan. Oleh karena itu, pada permainan bola voli dan basket memerlukan komponen horizontal dan vertikal (King \& Cipriani, 2010).

\section{Penggunaan LP pada Peningkatan Kecepatan Sprint dan Kelincahan}

Hasil analisis dari beberapa studi menemukan bahwa terdapat beberapa parameter 
Jurnal Ilmiah Mandala Education

http://ejournal.mandalanursa.org/index.php/JIME/index

Terakreditasi Peringkat 4 (No. SK: 36/E/KPT/2019) yang memberikan pengaruh yang optimal terhadap sprint (Booth \& Orr, 2016). Parameter yang dimksud adalah: (a) periode pelatihan selama 10 Minggu, (b) total minimal 15 set, (c) latihan intensitas tinggi, dan (d) terdiri lebih dari 80 lompatan gabungan per sesi (De Villarreal, Requena, \& Cronin, 2012). Dalam peningkatan performa sprint, penggunaan komponen horizontal memberikan pengaruh yang lebih besar dengan beban latihan yang cukup. Pemberian beban tambahan terbukti tidak efektif dalam peningkatan performa peningkatan sprint (Booth \& Orr, 2016). LP terbukti mampu meningkatkan performa sprint durasi 5 - 30 menit pada remaja (Chaouachi et al., 2014) dan 40 menit pada pemain sepak bola yunior (Diallo et al., 2001; Chelly et a., 2010). Peningkatan 0,5 0,7 detik juga ditemukan dalam peningkatan kelincahan, termasuk $6 \times 5$ shuttle rum, t test, dan uji kelincahan illinois dari pre ke pos tes. Tidak ada pengurangan waktu pada kedua kelompok (Miller et al., 2006). Tapi belum ada penelitian yang membuktikan bahwa LP lebih baik daripada latihan sprint itu sendiri (Ramírez-Campillo, Andrade, \& Izquierdo, 2013). Hal tersebut sesuai dengan teori latihan kekhususan pada olahraga. Dengan demikian LP lebih sesuai jika digunakan sebagai latihan tambahan daripada latihan utama.

\section{Penggunaan LP pada Peningkatan Vertical Jump}

Bentuk latihan yang paling sering digunakan untuk LP adalah Vertical Jump (VJ) dengan variasi lompatan eksplosif. Oleh karena itu, LP baik digunakan sebagai pelatihan dan pengukuran peningkatan kinerja (Booth \& Orr, 2016). Sebuah meta analisis oleh Markovic dalam 26 penelitian tentang LP menemukan terdapat peningkatan pada depth jump dan squat jump sebesar $4,7 \%$ dan performa Countermovement Jump (CMJ) sebesar 8,7\% (de Villareal et al., 2013). Hasil ini secara konsisten muncul pada hasil penelitian tentang LP. Penelitian terhadap Squat Jump (SJ) menemukan bahwa SJ mampu meningkatkan performa remaja selama program 10 minggu dengan frekuensi 2 latihan tiap Minggu. Volume yang digunakan pada penelitian terhadap SJ berkisar antara 60 - 100 lompatan tiap sesi (Kotzamanidis, 2006). Hasil yang mirip juga ditemukan pada latihan terhadap laki-laki dewasa dengan frekuensi 4 latihan setiap Minggu selama 12 Minggu (Kubo et al., 2007). Penelitian lebih banyak dilakukan terhadap CMJ dengan peningkatan sebesar 7,5\% dan $10 \%$ pada atlet laki-laki dewasa (Ford et al., 1983). Vising et al. (2008) mengamati bahwa terdapat peningkatan sebesar $10 \%$ pada pelatihan CJM terhadap subjek laki-laki dewasa dengan frekuensi latihan selama 2 x 12 Minggu. Perbaikan tersebut tidak terbatas pada CMJ bilateral. Untuk perempuan dewasa mampu meningkatkan CMJ satu kaki dan dua kaki bergantian setelah $3 \times 12$ Minggu dari LP (Makaruk et al., 2011). Namun tidak semua studi menemukan bahwa PT mampu meningkatkan VJ. Perempuan dari lingkungan perguruan tinggi (Vescovi, Canavan, \& Hasson, 2008) dan seorang atlet lari laki-laki (Turner, Owings, \& Schwane, 2003) tidak menunjukkan peningkatan VJ dengan perlakuan selama 6 Minggu. Dari sini dapat disimpulkan bahwa perlakuan LP selama 6 Minggu masih belum bisa memberikan dampak yang menunjukkan peningkatan VJ.

\section{Penggunaan LP pada Olahraga Lapangan Kecil}

Atlet pada olahraga lapangan kecil dalam ruangan cenderung mengalami peningkatan setelah penggunaan LP sebagai program latihan. Olahraga seperti basket, tenis, voli, dan bola tangan cenderung memerlukan tingkat kelincahan, kecepatan, maupun kemampuan melompat yang tinggi (Booth \& Orr, 2016). Oleh karena itu banyak studi yang membahas tentang pengaruh LP pada permainan olahraga lapangan kecil. Dalam sebuah perbandingan antara LP tradisional dan LP bersyarat menggunakan rompi berbeban pada subjek 27 pemain basket profesional menunjukkan kedua kelompok mampu meningkatkan CMJ, SJ, dan performa repetisi lima lompatan. Namun secara signifikan, kelompok LP bersyarat menunjukkan perubahan yang lebih tinggi (Khlifa et al., 2010). Drop Height (DH) menunjukkan peran penting dalam besarnya peningkatan penggunaan LP pada 33 
Jurnal Ilmiah Mandala Education

http://ejournal.mandalanursa.org/index.php/JIME/index

Terakreditasi Peringkat 4 (No. SK: 36/E/KPT/2019)

atlet basket yunior. Program latihan dengan menggunakan Drop Jump (DJ) pada ketinggian 50 atau $100 \mathrm{~cm}$ selama 2 x 6 Minggu meningkatkan VJ masing-masing 4,8 cm dan 5,6 cm (Matavulj et al., 2001). Studi yang lebih luas pada anggota tubuh atas dan bawah oleh Santos dan Janeira (2011) menemukan bahwa terdapat peningkatan pada $\mathrm{DJ}, \mathrm{VJ}, \mathrm{CMJ}$, dan lemparan medicine ball setelah 10 Minggu perlakuan. Subjek yang digunakan adalah 24 pemain basket yunior. Efek ini bertahan hingga 6 Minggu setelah perlakuan LP dihentikan dan kegiatan basket reguler dilanjutkan.

VJ meningkat (11\%) jika dibandingkan dengan kelompok kontrol (4\%) pada 19 pemain bola voli remaja selama 6 Minggu perlakuan menggunakan LP aquatic (Martel et al., 2005). Perlakuan pada 22 pemain bola tangan pria menunjukkan peningkatan sebesar $2,78 \%$ untuk CMJ, 2,68\% untuk DJ dengan gabungan program LP dan sprint selama 12 Minggu (Monsef et al., 2012). LP juga memberikan dampak positif terhadap tenis. Penggunaan LP pada tenis dapat meningkatkan kecepatan dan kelincahan dalam bergerak (Salonikidis \& Zafeiridis, 2008) dan memperbaiki serve (Gelen et al., 2012). Pada 26 atlet yunior elit terjadi peningkatan kecepatan bola selama servis sebesar 1-3\% ketika program latihan LP tubuh bagian atas diterapkan saat pemanasan (Gelen et al., 2012).

\section{Penggunaan LP pada Olahraga Lapangan Besar}

Penerapan LP pada olahraga lapangan besar lebih menekankan pada peningkatan kecepatan dan kelincahan daripada kemampuan dalam melompat. Keadaan ini tidak terlepas bahwa olahraga lapangan besar jarang melibatkan lompatan dalam pertandingan (Booth \& Orr, 2016). Peningkatan sprint 10 meter $(22,1 \%)$ dan berbagai agility test $(29,6 \%)$ telah ditemukan pada atlet muda (Meylan \& Malatesta, 2009). Pengaruh yang mirip telah diteliti pada laki-laki terlatih dengan menggunakan Illinois agility test dengan hasil 20.29(s) (t test) dan 20.26(s) (Vescovi et al., 2008). Dampak pada ketinggian lompatan dan kekuatan tendangan pada sepak bola telah diamati. LP terbukti mampu meningkatkan kecepatan bola (Perez-Gomez et al., 2008; Campo et al., 2009) dan jarak tendangan total (Rubley et al., 2011). Dalam penelitian ini peningkatan VJ dan jarak tendangan pada remaja perempuanterlihat setelah 14 Minggu perlakuan, dan tidak nampak pada 7 Minggu perlakuan. Dari sini terlihat bahwa remaja perempuan memerlukan waktu untuk adat beradaptasi lebih lama daripada laki-laki.

Pada permainan Rugby, LP difokuskan terhadap daya ledak tubuh bagian bawah, kelincahan, dan kecepatan. Studi terhadap pemain Rugby universitas dengan usia di bawah 19 tahun $(\mathrm{n}=35)$ menunjukkan peningkatan yang signifikan pada waktu sprint 20 meter, tes anaerobik dengan siklus Wingate, serta t test pada kelincahan setelah 4 Minggu perlakuan (Pienaar \& Coetzee, 2013). Perbandingan aktivitas berat sebelum kegiatan eksplosif dan LP menunjukkan bahwa satu set $40 \mathrm{SJ}$ menghasilkan peningkatan yang setara dalam kinerja CMJ. Hasil serupa ditemukan untuk perlakuan dengan waktu istirahat 1, 3, dan 5 menit sebelum CMJ (Tobin \& Delahunt, 2014). Penelitian ini menunjukkan bahwa pelatihan yang kompleks mungkin tidak diperlukan untuk memperoleh manfaat kinerja pasca potensiasi.

\section{Penggunaan LP pada Olahraga Air}

Beberapa studi menemukan bahwa LP dapat digunakan dalam olahraga air seperti berenang karena dapat meningkatkan kemampuan tendangan kaki dalam mendorong air dan pergerakan horizontal (Cossor, Blanksby, \& Elliott, 1999; Robinson et al., 2004; Rebutini et al., 2016). Peningkatan yang signifikan pada sendi pinggul dan lutut nampak setelah LP lompat jauh selama 9 Minggu. Peningkatan gaya horizontal (7\%) dan kecepatan lepas landas (16\%) memiliki peran penting dalam waktu start awal dan gerakan putar balik (Potdevin et al., 2011), waktu kinerja renang hingga 5,5 $\mathrm{m}$ (eks = $-0,59$; kontrol $=-0,21)$ dan kecepatan lepas landas (0,19 mili detik dibanding -0,07 milidetik) (Bishop et al., 2009).

\section{Penggunaan LP sebagai Pencegahan Cidera}


Jurnal Ilmiah Mandala Education

http://ejournal.mandalanursa.org/index.php/JIME/index

Terakreditasi Peringkat 4 (No. SK: 36/E/KPT/2019)
LP tidak hanya digunakan untuk meningkatkan performa dalam olahraga. Studi menemukan bahwa LP lebih baik dalam meningkatkan kinerja atlet setelah keseleo jika dibanding dengan Resistance Training (RT) (Ismail et al., 2010). Ketika akan menggunakan LP sebagai latihan untuk pencegahan cidera, perlu diperhatikan tentang jenis latihan yang diberikan. Pertimbangan juga diberikan terhadap mekanisme pendaratan (tubuh bagi bawah) dan torsi yang terjadi (tubuh bagian atas). Dasar dari mekanisme pendaratan melibatkan ketepatan kontraksi otot, sudut sendi, dan pemuatan daya untuk menahan hentakan (Booth \& Orr, 2016). Perbedaan pada hamstring dan otot gluteal telah diidentifikasi selama fase persiapan dan pendaratan. Model latihan Single-leg sagittal plane hurdle hops menghasilkan aktivitas gluteal dan hamstring terbesar pada kedua fase. Latihan ini mungkin penting untuk dilakukan guna mencegah cidera Anterior Cruciate Ligament (ACL) (Struminger et al., 2013). Penelitian lebih lanjut terhadap tujuh bentuk LP (2-foot ankle hop, repeated SJ, double-leg hop, DJ from 30 and 60 $\mathrm{cm}$, and single- and double-leg tuck jumps) menunjukkan perbedaan yang nampak dalam output mekanis pada pergelangan kaki dan pinggul (Booth \& Orr, 2016). Sendi pada pergelangan kaki digunakan untuk lompatan tuck jump, sedangkan pinggul untuk lompatan SJ atau lompatan kaki ganda (Sugisaki, Okada, \& Kanehisa, 2013).

Tabel 1 Rekomendasi Penggunaan LP

\begin{tabular}{|c|c|c|c|c|c|c|}
\hline alam & Lati & & & husus & $\mathrm{O}$ & praga \\
\hline $\begin{array}{c}\text { Jenis } \\
\text { Olahraga }\end{array}$ & Tahapan Latihan & Durasi & Frek & Volume & Intensitas & Rest \\
\hline $\begin{array}{l}\text { OR } \\
\text { Lapangan } \\
\text { Kecil } \\
\end{array}$ & $\begin{array}{lr}\text { Masa } & \text { transisi } \\
\text { atau suaselum } \\
\text { kompetisi }\end{array}$ & $\begin{array}{l}10 \\
\text { Mingg } \\
\mathrm{u}\end{array}$ & $\begin{array}{l}2-3 \\
\text { kali }\end{array}$ & $\begin{array}{l}50 \text { kontak } \\
\text { tiap sesi }\end{array}$ & $\begin{array}{l}\text { High intensity } \\
\text { berbeban }\end{array}$ & $\begin{array}{l}3-4 \min \\
\text { atau } 1: 10\end{array}$ \\
\hline $\begin{array}{l}\text { OR } \\
\text { Lapangan } \\
\text { Besar }\end{array}$ & $\begin{array}{lr}\text { Masa } & \text { transisi } \\
\text { atau sebelum } \\
\text { kompetisi }\end{array}$ & $\begin{array}{l}10 \\
\text { Mingg } \\
\mathrm{u}\end{array}$ & 2 kali & $\begin{array}{l}80 \text { kontak } \\
\text { tiap sesi }\end{array}$ & $\begin{array}{l}\text { High intensity } \\
\text { berbeban }\end{array}$ & $\begin{array}{l}1-2 \min \\
\text { atau } 1: 10\end{array}$ \\
\hline OR Air & $\begin{array}{lr}\text { Masa } & \text { transisi } \\
\text { atau su sebelum } \\
\text { kompetisi }\end{array}$ & $\begin{array}{l}20 \\
\text { Mingg } \\
\mathrm{u}\end{array}$ & 3 kali & $\begin{array}{l}300 \\
\text { kontak } \\
\text { tiap sesi }\end{array}$ & $\begin{array}{l}\text { Low to } \\
\text { moderate tanpa } \\
\text { beban }\end{array}$ & $\begin{array}{l}2 \mathrm{~min} \\
\text { atau 1:10 }\end{array}$ \\
\hline
\end{tabular}

\section{KESIMPULAN}

Kesimpulannya, lamanya program LP, dosis pelatihan (intensitas, durasi, dan frekuensi latihan), jenis latihan, dan penempatan dalam program berkala akan bervariasi sesuai dengan olahraga, tingkat pelatihan atlet, atribut fisiologis tertentu yang sedang dilatih (kecepatan sprint, kekuatan otot, atau tinggi lompatan). Volume latihan, frekuensi, dan intensitas yang tepat belum dijelaskan secara khusus dan memerlukan studi lebih lanjut. Namun temuan yang diperoleh dalam artikel ini memberikan saran bahwa LP dapat dijadikan sebagai program latihan penting untuk dapat dimasukkan dalam peningkatan kekuatan dan performa dalam olahraga darat maupun air.

\section{SARAN}

Diperlukan kajian lebih lanjut untuk mengetahui perbedaan yang jelas pada tiap-tiap cabang olahraga yang menggunakan LP dalam program latihannya. Diperlukan sebuah eksperimen yang membandingkan masingmasing bentuk LP untuk mengetahui bentuk LP mana yang paling sesuai untuk meningkatkan kapasitas fisik seorang atlet.

\section{DAFTAR PUSTAKA}

Bishop, D. C., Smith, R. J., Smith, M. F., \& Rigby, H. E. (2009). Effect of plyometric training on swimming block start performance in adolescents. The Journal of Strength \& Conditioning Research, 23(7), 2137-2143.

Bompa, T. O. (1994). Theory and methodology of training: the key to athletic performance. Kendall hunt publishing company.

Booth, M. A., \& Orr, R. (2016). Effects of plyometric training on sports performance. Strength \& Conditioning Journal, 38(1), 30-37.

Cadore, E. L., Pinheiro, E., Izquierdo, M., Correa, C. S., Radaelli, R., Martins, J. B., ... \& Pinto, R. S. (2013). Neuromuscular, hormonal, and metabolic responses to different plyometric training volumes in rugby players. The Journal of Strength \& Conditioning Research, 27(11), 3001-3010.

Campo, S. S., Vaeyens, R., Philippaerts, R. M., Redondo, J. C., de Benito, A. M., \& Cuadrado, G. (2009). Effects of lower-limb plyometric training on body composition, explosive strength, and kicking speed in female soccer players. The Journal of Strength \& Conditioning Research, 23(6), 1714-1722.

Chaouachi, A., Hammami, R., Kaabi, S., Chamari, K., Drinkwater, E. J., \& Behm, D. G. (2014). Olympic weightlifting and plyometric training 
Jurnal Ilmiah Mandala Education

http://ejournal.mandalanursa.org/index.php/JIME/index

Terakreditasi Peringkat 4 (No. SK: 36/E/KPT/2019)

with children provides similar or greater performance improvements than traditional resistance training. The Journal of Strength \& Conditioning Research, 28(6), 1483-1496.

Chelly, M. S., Ghenem, M. A., Abid, K., Hermassi, S., Tabka, Z., \& Shephard, R. J. (2010). Effects of in-season short-term plyometric training program on leg power, jump-and sprint performance of soccer players. The Journal of Strength \& Conditioning Research,24(10), 2670-2676.

Chen, T. L. W., Wong, D. W. C., Wang, Y., Ren, S., Yan, F., \& Zhang, M. (2017). Biomechanics of fencing sport: A scoping review. PloS one, 12(2), $\mathrm{e} 0171578$.

Chmielewski, T. L., Myer, G. D., Kauffman, D., \& Tillman, S. M. (2006). Plyometric exercise in the rehabilitation of athletes: physiological responses and clinical application. Journal of Orthopaedic \& Sports Physical Therapy, 36(5), 308-319.

Chu, D. (1989). Plyometric exercises with the medicine ball. Bittersweet Publishing Company.

Cossor, J. M., Blanksby, B. A., \& Elliott, B. C. (1999). The influence of plyometric training on the freestyle tumble turn. Journal of Science and Medicine in Sport, 2(2), 106-116.

Davies, G. J., \& Matheson, J. W. (2001). Shoulder plyometrics. Sports Medicine and Arthroscopy Review, 9(1), 1-18.

Davies, G., Riemann, B. L., \& Manske, R. (2015). Current concepts of plyometric exercise. International journal of sports physical therapy, 10(6), 760.

De Villarreal, E. S. S., Requena, B., \& Newton, R. U. (2010). Does plyometric training improve strength performance? A metaanalysis. Journal of science and medicine in sport, 13(5), 513-522.

De Villarreal, E. S., Requena, B., \& Cronin, J. B. (2012). The effects of plyometric training on sprint performance: A meta-analysis. The Journal of Strength \& Conditioning Research, 26(2), 575-584.

de Villarreal, E. S., Requena, B., Izquierdo, M., \& Gonzalez-Badillo, J. J. (2013). Enhancing sprint and strength performance: combined versus maximal power, traditional heavyresistance and plyometric training. Journal of science and medicine in sport, 16(2), 146-150.
Diallo, O., Dore, E., Duche, P., \& Van Praagh, E. (2001). Effects of plyometric training followed by a reduced training programme on physical performance in prepubescent soccer players. Journal of sports medicine and physical fitness, 41(3), 342.

Donoghue, O. A., Shimojo, H., \& Takagi, H. (2011). Impact forces of plyometric exercises performed on land and in water. Sports health, 3(3), 303-309.

Duda, M. (1988). Plyometrics: a legitimate form of power training?. The Physician and Sportsmedicine, 16(3), 212-218.

Ebben, W. P., Simenz, C., \& Jensen, R. L. (2008). Evaluation of plyometric intensity using electromyography. The Journal of Strength \& Conditioning Research, 22(3), 861-868.

Ebben, W. P., \& Petushek, E. J. (2010). Using the reactive strength index modified to evaluate plyometric performance. The Journal of Strength \& Conditioning Research,24(8), 1983-1987.

Ebben, W. P., Fauth, M. L., Garceau, L. R., \& Petushek, E. J. (2011). Kinetic quantification of plyometric exercise intensity. The Journal of Strength \& Conditioning Research,25(12), 3288-3298.

Fernandez-Fernandez, J., De Villarreal, E. S., SanzRivas, D., \& Moya, M. (2016). The effects of 8-week plyometric training on physical performance in young tennis players. Pediatric Exercise Science, 28(1), 77-86.

Ford Jr, H. T., Puckett, J. R., Drummond, J. P., Sawyer, K., Gantt, K., \& Fussell, C. (1983). Effects of three combinations of plyometric and weight training programs on selected physical fitness test items. Perceptual and Motor Skills, 56(3), 919-922.

Fowler, N. E., Trzaskoma, Z., Wit, A., Iskra, L., \& Lees, A. (1995). The effectiveness of a pendulum swing for the development of leg strength and counter-movement jump performance. Journal of sports sciences, 13(2), 101-108.

García-Massó, X., Colado, J. C., González, L. M., Salvá, P., Alves, J., Tella, V., \& Triplett, N. T. (2011). Myoelectric activation and kinetics of different plyometric push-up exercises. The Journal of Strength \& Conditioning Research, 25(7), 2040-2047. 
Jurnal Ilmiah Mandala Education

http://ejournal.mandalanursa.org/index.php/JIME/index

Terakreditasi Peringkat 4 (No. SK: 36/E/KPT/2019)

Gelen, E., Dede, M., Bingul, B. M., Bulgan, C., \& Aydin, M. (2012). Acute effects of static stretching, dynamic exercises, and high volume upper extremity plyometric activity on tennis serve performance. Journal of sports science \& medicine, 11(4), 600.

Guilhem, G., Giroux, C., Couturier, A., Chollet, D., \& Rabita, G. (2014). Mechanical and muscular coordination patterns during a high-level fencing assault. Medicine \& Science in Sports \& Exercise, 46(2), 341-350.

Khlifa, R., Aouadi, R., Hermassi, S., Chelly, M. S., Jlid, M. C., Hbacha, H., \& Castagna, C. (2010). Effects of a plyometric training program with and without added load on jumping ability in basketball players. The Journal of Strength \& Conditioning Research, 24(11), 2955-2961.

King, J. A., \& Cipriani, D. J. (2010). Comparing preseason frontal and sagittal plane plyometric programs on vertical jump height in highschool basketball players. The Journal of Strength \& Conditioning Research, 24(8), 2109-2114.

Kotzamanidis, C. (2006). Effect of plyometric training on running performance and vertical jumping in prepubertal boys. The Journal of Strength \& Conditioning Research, 20(2), 441-445.

Kubo, K., Morimoto, M., Komuro, T., Yata, H., Tsunoda, N., Kanehisa, H., \& Fukunaga, T. (2007). Effects of plyometric and weight training on muscle-tendon complex and jump performance. Medicine \& Science in Sports \& Exercise, 39(10), 1801-1810.

Makaruk, H., Winchester, J. B., Sadowski, J., Czaplicki, A., \& Sacewicz, T. (2011). Effects of unilateral and bilateral plyometric training on power and jumping ability in women. The Journal of Strength \& Conditioning Research, 25(12), 3311-3318.

Martel, G., Harmer, M., Logan, J., \& Parker, C. (2005). Aquatic plyometric training increases vertical jump in female volleyball players. Medicine \& Science in Sports \& Exercise, 37(10), 1814-1819.

Matavulj, D., Kukolj, M., Ugarkovic, D., Tihanyi, J., \& Jaric, S. (2001). Effects of pylometric training on jumping performance in junior basketball players. Journal of sports medicine and physical fitness, 41(2), 159-164.

Meylan, C., \& Malatesta, D. (2009). Effects of inseason plyometric training within soccer
Vol. 6. No. 2. Oktober 2020

p-ISSN: 2442-9511 e-ISSN: 2656-5862

practice on explosive actions of young players. The Journal of Strength \& Conditioning Research, 23(9), 2605-2613.

Miller, M. G., Herniman, J. J., Ricard, M. D., Cheatham, C. C., \& Michael, T. J. (2006). The effects of a 6-week plyometric training program on agility. Journal of sports science \& medicine, 5(3), 459.

Monsef Cherif, M. S., Chaatani, S., Nejlaoui, O., Gomri, D., \& Abdallah, A. (2012). The effect of a combined high-intensity plyometric and speed training program on the running and jumping ability of male handball players. Asian journal of sports medicine, 3(1), 21.

Notar, C. E., \& Cole, V. (2010). Literature review organizer. International journal of Education, 2(2), 1.

Pezzullo, D. J., Karas, S., \& Irrgang, J. J. (1995). Functional plyometric exercises for the throwing athlete. Journal of Athletic Training, 30(1), 22.

Pienaar, C., \& Coetzee, B. (2013). Changes in selected physical, motor performance and anthropometric components of university-level rugby players after one microcycle of a combined rugby conditioning and plyometric training program. The Journal of Strength \& Conditioning Research, 27(2), 398-415.

Pomatahu, A. (2018). Box Jump, Depth Jump Sprint, Power Otot Tungkai Pada Cabang Olahraga Pencak Silat. Yogyakarta: Zahir Publishing.

Potdevin, F. J., Alberty, M. E., Chevutschi, A., Pelayo, P., \& Sidney, M. C. (2011). Effects of a 6-week plyometric training program on performances in pubescent swimmers. The Journal of Strength \& Conditioning Research, 25(1), 80-86.

Ramírez-Campillo, R., Andrade, D. C., \& Izquierdo, M. (2013). Effects of plyometric training volume and training surface on explosive strength. The Journal of Strength \& Conditioning Research, 27(10), 2714-2722.

Rebutini, V. Z., Pereira, G., Bohrer, R. C., Ugrinowitsch, C., \& Rodacki, A. L. (2016). Plyometric long jump training with progressive loading improves kinetic and kinematic swimming start parameters. Journal of Strength and Conditioning Research, 30(9), 2392-2398.

Robinson, L. E., Devor, S. T., Merrick, M. A., \& Buckworth, J. (2004). The effects of land vs. aquatic plyometrics on power, torque, velocity, 
Jurnal Ilmiah Mandala Education

http://ejournal.mandalanursa.org/index.php/JIME/index

Terakreditasi Peringkat 4 (No. SK: 36/E/KPT/2019)

and muscle soreness in women. Journal of Strength and Conditioning Research, 18(1), 8491.

Rubley, M. D., Haase, A. C., Holcomb, W. R., Girouard, T. J., \& Tandy, R. D. (2011). The effect of plyometric training on power and kicking distance in female adolescent soccer players. The Journal of Strength \& Conditioning Research, 25(1), 129-134.

Salonikidis, K., \& Zafeiridis, A. (2008). The effects of plyometric, tennis-drills, and combined training on reaction, lateral and linear speed, power, and strength in novice tennis players. The Journal of Strength \& Conditioning Research, 22(1), 182-191.

Sammoud, S., Negra, Y., Chaabene, H., Bouguezzi, R., Moran, J., \& Granacher, U. (2019). The effects of plyometric jump training on jumping and swimming performances in prepubertal male swimmers. Journal of Sports Science \& Medicine, 18(4), 805.

Santos, E. J., \& Janeira, M. A. (2011). The effects of plyometric training followed by detraining and reduced training periods on explosive strength in adolescent male basketball players. The Journal of Strength \& Conditioning Research, 25(2), 441-452.

Struminger, A. H., Lewek, M. D., Goto, S., Hibberd, E., \& Blackburn, J. T. (2013). Comparison of gluteal and hamstring activation during five commonly used plyometric exercises. Clinical biomechanics, 28(7), 783-789.

Sugisaki, N., Okada, J., \& Kanehisa, H. (2013). Intensity-level assessment of lower body plyometric exercises based on mechanical output of lower limb joints. Journal of sports sciences, 31(8), 894-906.

Supriyanto, S. (2018). Pengaruh Metode LP dan Latihan Beban dengan Kecepatan Reaksi terhadap Power Otot Tungkai Pemain Bolavoli Putra. Gelanggang Olahraga: Jurnal Pendidikan Jasmani Dan Olahraga, 2(1), 176189.

Tobin, D. P., \& Delahunt, E. (2014). The acute effect of a plyometric stimulus on jump performance in professional rugby players. The Journal of Strength \& Conditioning Research, 28(2), 367372.

Tsolakis, C., Kostaki, E., \& Vagenas, G. (2010). Anthropometric, flexibility, strength-power, and sport-specific correlates in elite
Vol. 6. No. 2. Oktober 2020

p-ISSN: 2442-9511 e-ISSN: 2656-5862

fencing. Perceptual and motor skills, 110(3_suppl), 1015-1028.

Turner, A. M., Owings, M., \& Schwane, J. A. (2003). Improvement in running economy after 6 weeks of plyometric training. The Journal of Strength \& Conditioning Research, 17(1), 60-67.

Turner, A. P., Bellhouse, S., Kilduff, L. P., \& Russell, M. (2015). Postactivation potentiation of sprint acceleration performance using plyometric exercise. The Journal of Strength \& Conditioning Research, 29(2), 343-350.

Turner, A. N., Marshall, G., Phillips, J., Noto, A., Buttigieg, C., Chavda, S., ... \& Kilduff, L. (2016). Physical characteristics underpinning repetitive lunging in fencing. Journal of strength and conditioning research,30(11), 3134-3139.

Vescovi, J. D., Canavan, P. K., \& Hasson, S. (2008). Effects of a plyometric program on vertical landing force and jumping performance in college women. Physical Therapy in Sport, 9(4), 185-192.

Vissing, K., Brink, M., Lønbro, S., Sørensen, H., Overgaard, K., Danborg, K., ... \& Andersen, J. L. (2008). Muscle adaptations to plyometric vs. resistance training in untrained young men. The Journal of Strength \& Conditioning Research, 22(6), 1799-1810.

Wathen, D., \& Trainer, A. (1993). Literature review: explosive/plyometric exercises. Training, 25(2), 122. 